Applied Physics A Materials Science \& Processing 117:55-62 @ Springer-Verlag Berlin Heidelberg 2014 DOI:10.1007/s00339-014-8499-8

\title{
Comparison of silver nanoparticles confined in nanoporous silica prepared by chemical synthesis and by ultra-short pulsed laser ablation in liquid
}

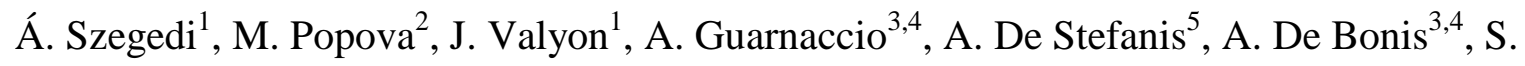 \\ Orlando $^{3}$, M. Sansone ${ }^{4}$, R. Teghil ${ }^{4}$, A. Santagata ${ }^{3 *}$
}

${ }^{1}$ Research Centre for Natural Sciences, Institute of Materials and Environmental Chemistry, Hungarian Academy of Sciences, 1117 Budapest, Magyar tudósok körútja 2., Hungary

${ }^{2}$ Institute of Organic Chemistry with Centre of Phytochemistry, Bulgarian Academy of Sciences, 1113 Sofia, Bulgaria

${ }^{3}$ UOS Tito Scalo, Institute of Structure of Matter - CNR, C/da S. Loja, 85050 Tito Scalo (PZ), Italy

${ }^{4}$ Università degli Studi della Basilicata, Dipartimento di Scienze, Via dell'Ateneo Lucano 1085100, Potenza, Italy

${ }^{5}$ Institute of Structure of Matter - CNR, Rome Research Area-CNR, Via Salaria Km 29, 300, Monterotondo, Rome 00016, Italy

*Corresponding author (Phone number: +39 0971 427227, e-mail: antonio.santagata@ cnr.it) Key Words: silver nanoparticles, MCM-41, SBA-15, VOC oxidation, laser ablation in liquid

\begin{abstract}
Hexagonally ordered mesoporous silica materials MCM-41 and SBA-15 have been synthesized and loaded with Ag nanoparticles, utilizing both chemical synthesis and ultrashort pulsed laser ablation in liquid.

In laser ablation, a silver target, immersed in aqueous suspension of ordered mesoporous silica SBA-15, was irradiated by ultra-short laser pulses to generate silver nanoparticles. For comparison samples of similar silver contents were prepared either by incorporating silver into the SBA-15 during a hydrothermal synthesis or by introducing silver in MCM-41 by template ion-exchange. Samples were characterized by XRD, $\mathrm{N}_{2}$ physisorption, TEM and UV-vis spectroscopy. All preparations contained significant amount of 5-50 nm size silver
\end{abstract}


agglomerates on the outer surface of the silica particles. The laser ablation process did not cause significant destruction of the SBA-15 structure and metallic silver $\left(\mathrm{Ag}^{0}\right)$ nanoparticles were mainly generated. It is demonstrated that by laser ablation in aqueous silica suspension smaller and more uniform metallic silver particles can be produced and loaded on the surface of the silica support than by synthesis procedures. Catalytic properties of the samples have been tested in the total oxidation of toluene. Because of its favorable Ag dispersity the Ag/SBA-15 catalyst, generated by the laser ablation method, had better catalytic stability and, relative to its Ag load, higher activity than the conventional Ag/SBA-15 preparations.

\section{Introduction}

Laser ablation of materials in liquid has demonstrated to be a suitable technique for several kind of nanoparticles production in both stable and metastable phases [1-3]. Ablation of metal plates in a solution has shown its ability in generating nanoparticles which, since the work of Mafune and others [4-11], has been consolidated during the last decade.

Stable metal (Ag, Au, Pt, Pd, etc.) colloidal solutions have been obtained in water and organic solvents instantaneously [12-14]. Laser ablation in liquid is a low cost technique because it does not need vacuum equipment, not wet chemistry processes are required and the formed nanoparticles, being stored in the liquid as a colloidal dispersion, are easily collected after the synthesis. With respect to conventional chemical techniques another important advantage of this method is that the formed colloidal solutions are free of undesirable organic or ionic impurities. The laser ablation is particularly suitable to generate stable nanoparticle dispersions with defined size, shape and characteristics, through fine tuning of the ablation parameters. A variety of highly pure nanoparticles can be, in this way, synthesized and integrated into different materials as functional component $[15,16]$.

Insertion of metal nanoparticles into porous structures such as zeolites, zeotypes and other adsorbents and catalysts, has long been pursuing as a goal in order to produce materials suitable for different applications, such as, microelectronics, medical diagnosis, and others [17] where finely tuned characteristics of the structure are required. The traditional methods of dispersing metals in these three-dimensional mesoporous structures are ion exchange, incipient wetness impregnation and subsequent in-situ reduction to form metal particles inside the pores. Each method allows the introduction of large quantities of the metal inside and also outside the porous structure although lacking in controlling the metal particle size and shape. The direct encapsulation of Au nanoparticles into MCM-41 and MCM-48 was first achieved by synthesizing the mesoporous structure in the presence of colloidal gold [18]. Since then, 
many other strategies have been adopted to generate such structures containing metals in appropriate quantity and dispersion. Porous carbon supported platinum and platinumruthenium electrocatalysts have been prepared by the microemulsion technique, generating nanosized particles of narrow size distribution [19]. However, some aggregates of particles of small sizes occur, in particular, in samples containing a large amount of the metal. This aggregation takes place, most likely, during the metal deposition step. Sonochemical insertion of Ag nanoparticles into two-dimensional mesoporous alumina was first reported in the year 2007 by Gedanken et al. [20]. If Ag loading exceeded 3wt.\% the surface area of the mesoporous alumina decreased. Other researches have attempted to incorporate $\mathrm{Ag}$ nanoparticles into different mesoporous systems such as hexagonal $\mathrm{ZnO}$ nanocomposites and nanorods by applying microwave irradiation [21]. Insertion of metal oxide based nanoparticles (e.g. crystalline anatase $\left(\mathrm{TiO}_{2}\right)$ ) on high-surface-area mesoporous silica structures have even been achieved by the solvent evaporation-induced method under acidic conditions [22].

The possibility of inserting metal nanoparticles, generated by laser-ablation, into a porous material was first explored by Hashimoto and co-workers applying the crystallizationinclusion methodology to get Au NPs-doped zeolite L crystals [23].

The goal of dispersing Ag nanoparticles in the SBA-15 structure has been pursued in the last few years by various groups [24-26] applying new synthesis and encapsulation techniques.

In order to insert silver nanoparticles in nanoporous silica MCM-41 and SBA-15 chemical routes and ultra-short pulsed laser ablation in liquid were employed in this work. These samples were then characterized by structural and catalytic methods. A comparison of their catalytic activities in the total oxidation of toluene is reported.

\section{Experimental}

\subsection{Synthesis of Ag/MCM-41 by template ion-exchange method (TIE)}

Spherical nanosized (100 nm) MCM-41 particles were prepared according to the procedure of Huh et al. [27]. This sol-gel procedure is carried out at $80^{\circ} \mathrm{C}$ in water solution with $\mathrm{NaOH}$ as catalyst. Tetraethyl orthosilicate (TEOS) was applied as silica source and hexadecyl trimethyl-ammonium bromide $\left(\mathrm{C}_{16} \mathrm{TMABr}\right)$ was used as template. The relative molar composition of the reaction mixture was: 1 TEOS: $0.12 \mathrm{C}_{16} \mathrm{TMABr}: 0.31 \mathrm{NaOH}: 1190 \mathrm{H}_{2} \mathrm{O}$. The formed gel was aged at $80^{\circ} \mathrm{C}$ for $2 \mathrm{~h}$, washed with distilled water up to reaching neutral 
$\mathrm{pH}$, and dried under ambient conditions. Silver nanoparticles were loaded to the silica carrier by the template ion-exchange method of Gac et. al. [28]. The template-containing MCM-41 material was ion-exchanged by refluxing it at $80^{\circ} \mathrm{C}$ with $0.036 \mathrm{M} \mathrm{AgNO}_{3}$ solution $(50 \mathrm{ml} / \mathrm{g}$ MCM-41) for $20 \mathrm{~h}$. It was followed by filtration through a $0.2-\mu \mathrm{m}$ membrane filter, and washed nitrate free with distilled water. The ion-exchanged material was heat treated in air raising the temperature to $550^{\circ} \mathrm{C}$ at a rate of $1^{\circ} \mathrm{C} / \mathrm{min}$ and keeping the final temperature for 5 h. The silver containing MCM-41 sample, prepared by the template ion-exchange method, has been designated with the TIE suffix that is Ag/MCM-41TIE.

\subsection{Synthesis of Ag/SBA-15 by hydrothermal method}

Mesoporous Ag/SBA-15 material was synthesized by direct hydrothermal synthesis in the presence of P123 triblock copolymer (BASF, P123, $\mathrm{EO}_{20} \mathrm{PO}_{70} \mathrm{EO}_{20}, \mathrm{M}_{\mathrm{w}}=5800$ ) as a template and TEOS as a silica source modifying the procedure of Zhu et al. [29]. To avoid the precipitation of $\mathrm{AgCl}$, instead of $\mathrm{HCl} \mathrm{HNO}_{3}$ was applied as acidic media. In a typical synthesis procedure $4 \mathrm{~g}$ of P123, $120 \mathrm{~g}$ of deionized water and $18.8 \mathrm{~g}$ of $65 \mathrm{wt} . \%$ nitric acid were mixed and stirred for $1 \mathrm{~h}$ at $40^{\circ} \mathrm{C} .0 .34 \mathrm{~g}$ of silver nitrate $(\mathrm{Si} / \mathrm{Ag}=20)$ was added to the solution and, in dark, it was stirred for $1 \mathrm{~h}$ at the same temperature. Then, $8.4 \mathrm{~g}$ of TEOS was slowly added to the solution and, still in dark, it was stirred for $20 \mathrm{~h}$ at $40^{\circ} \mathrm{C}$. The final molar ratio of the synthesis mixture was 1 TEOS: 0.017 P123: $0.05 \mathrm{AgNO}_{3}$ : $4.93 \mathrm{HNO}_{3}: 177.9 \mathrm{H}_{2} \mathrm{O}$. The precipitated white suspension was aged at $100^{\circ} \mathrm{C}$ for $48 \mathrm{~h}$ in a Teflon lined stainless steel autoclave without stirring. The product was filtered and washed free of nitrate by deionized water. The template was removed by calcining the sample in air at $450^{\circ} \mathrm{C}$ for $5 \mathrm{~h}$. The temperature was ramped up to the final temperature at a rate of $1{ }^{\circ} \mathrm{C} / \mathrm{min}$. The silver containing SBA-15 sample, prepared by the direct one-pot synthesis method, has been designated with the suffix DS, that is Ag/SBA-15DS.

\subsection{Preparation of Ag/SBA-15 by laser ablation method}

Pure silica SBA-15 was synthesized according to the original procedure of Zhao et al. [30] applying Pluronic 123 triblockcopolymer as a template and TEOS as a silica source in the acidic media of $2 \mathrm{~N} \mathrm{HCl}$. The template was removed by heating up the sample in air to $450^{\circ} \mathrm{C}$ at a rate of $1^{\circ} \mathrm{C} / \mathrm{min}$ and keeping it at this temperature for $5 \mathrm{~h}$.

In laser ablation, a silver platelet, immersed in an aqueous suspension of ordered mesoporous silica SBA-15, was irradiated by ultra-short laser pulses to generate silver nanoparticles. The laser beam (120 fs, $1 \mathrm{kHz}, 800 \mathrm{~nm}, 3.6 \mathrm{~mJ} /$ pulse) was perpendicularly focused by a $5.0 \mathrm{~cm}$ 
plano-convex focal length lens onto a Goodfellow Ag target foil (99.95\% purity, 6mm thickness). In order to continuously have an uniform distribution of the aqueous suspension of the silica SBA-15, the solution was stirred by a rotating magnet (400 rpm) during the laser ablation of the submerged Ag target. For having a laminar flow of the stirred solution along the laser beam path, a porous Teflon separator was placed between this and the rotating magnet. Either $5 \mathrm{wt} \%$ or $8 \mathrm{wt} \%$ of Ag solutions were obtained by 10 or 20 minutes of ablation time, respectively. The starting aqueous solutions were prepared, always, by employing $20 \mathrm{ml}$ of water and $5 \mathrm{mg}$ of porous silica SBA-15. The distance between the lens and the target and the column of liquid above the surface of the latter were of $5.1 \mathrm{~cm}$ and $1.4 \mathrm{~cm}$, respectively. The evaluated diameter of the laser spot size was of $4 \times 10^{-4} \mathrm{~cm}^{2}$.

Ag/SBA-15 samples, containing different amounts of silver, have been designated as 8Ag/SBA-15 LA and 5Ag/SBA-15 LA, respectively, where the first number gives the $\mathrm{Ag}$ content in weight percents and the LA suffix refers to the laser ablation preparation method.

\subsection{Characterization of samples}

X-ray powder diffraction patterns were recorded by a Philips PW 1810/3710 diffractometer working in the Bragg-Brentano parafocusing geometry applying monochromatized $\mathrm{CuK} \alpha$ $(\lambda=0.15418 \mathrm{~nm})$ radiation $(40 \mathrm{kV}, 35 \mathrm{~mA})$ and a proportional counter. The metallic silver was identified based on JSPDS ICDD database. The corresponding ICDD card number was: Ag4f 04-0783. The mean crystallite size of metallic silver was determined by the Sherrer equation evaluating the full width at half maximum (FWMH) values, employing the full profile fitting method.

Nitrogen physisorption isotherms were determined at $-196^{\circ} \mathrm{C}$ using Quantachrome Autosorb $1 \mathrm{C}$ apparatus. The samples were pre-treated before measurements by evacuation at $350^{\circ} \mathrm{C}$. The specific surface area was calculated by the BET method in the range of relative pressures from 0.02 to 0.1 . The pore-size distribution was calculated from desorption branch of the isotherms using the BJH method. The silver content of the prepared samples was determined by Atomic Absorption Spectroscopy (AAS), applying $\mathrm{AgNO}_{3}$ standard solution after digesting the silver containing samples in $\mathrm{HF}$ and $\mathrm{HNO}_{3}$.

TEM images were taken by using a MORGAGNI 268D TEM (100 kV; W filament; pointresolution $=0.5 \mathrm{~nm}$ ) electron microscope. Samples were suspended in small amount of ethanol and a drop of suspension was deposited onto a copper grid covered by carbon supporting film and dried at ambient temperature. 
Diffuse reflectance (DR) spectra in the UV-vis region were determined at ambient conditions by a Jasco V-670 spectrophotometer equipped with NV-470 type integrating sphere using a $\mathrm{BaSO}_{4}$ standard reference.

\subsection{Catalytic activity measurements}

Total oxidation of toluene was studied at atmospheric pressure using a fixed-bed flow-through reactor employing air as carrier gas and oxidizing agent. Prior to the catalytic tests the catalyst samples were pretreated in situ at $450^{\circ} \mathrm{C}$ and in air for 1 hour. In the reaction, a $30 \mathrm{mg}$ sample (particle size 0.2-0.8 mm) was tested diluted with $60 \mathrm{mg}$ glass beads of the same diameter. The activity of the glass beads was checked and they were found to be inactive. To study the reaction, the air stream was passed first through a saturator at $0^{\circ} \mathrm{C}$, filled with toluene $\left(\mathrm{p}_{\text {toluene }}=\right.$ $0.9 \mathrm{kPa}$ ) and then through the reactor at a flow rate of $30 \mathrm{ml} / \mathrm{min}$. The catalytic tests were carried out in the temperature range $250-450^{\circ} \mathrm{C}$ at a WHSV of $1.2 \mathrm{~g}_{\text {toluene }} \mathrm{g}_{\text {cat }}{ }^{-1} \mathrm{~h}^{-1}$. On-line analysis of the reaction products was performed using an HP-GC equipped with FID and TCD detectors applying a Carboxen 1100 packed column, and a HP5 50 m capillary column.

\section{Results and discussion}

\subsection{Physico-chemical characterization}

Small and wide angle XRD powder patterns of the silver-containing SBA-15 and MCM-41 silica materials are shown in Fig. 1. XRD patterns of Ag/SBA-15 and Ag/MCM-41 samples at low $2 \theta^{\circ}$ region show the formation of well-ordered $2 \mathrm{D}$ hexagonal structure with the intense (100) reflection and the appearance of the higher indexed (110) and (200) peaks. Compared to the pure silica SBA-15 and MCM-41 varieties some intensity decrease and unit cell size changes can be observed due to the chemical and physical modification of the mesoporous materials (Table 1). Only a small decrease can be observed in the unit cell parameter and pore size of Ag/MCM-41 TIE sample relative to the corresponding pure silica material. This can be due to the deterioration effect of the ion exchange procedure. Heating the sample in water solution at $80^{\circ} \mathrm{C}$ for $20 \mathrm{~h}$ could induce a less ordered honeycomb like structure. Incorporation of Ag into the structure of SBA-15 by direct synthesis is associated with more significant changes. The unit cell and the pore sizes increased, which can be due to either the isomorphous substitution of silicon atoms by larger silver ions, or changing the synthesis medium from $\mathrm{HCl}$ to $\mathrm{HNO}_{3}$. The Ag/SBA-15 samples, prepared by laser ablation method 


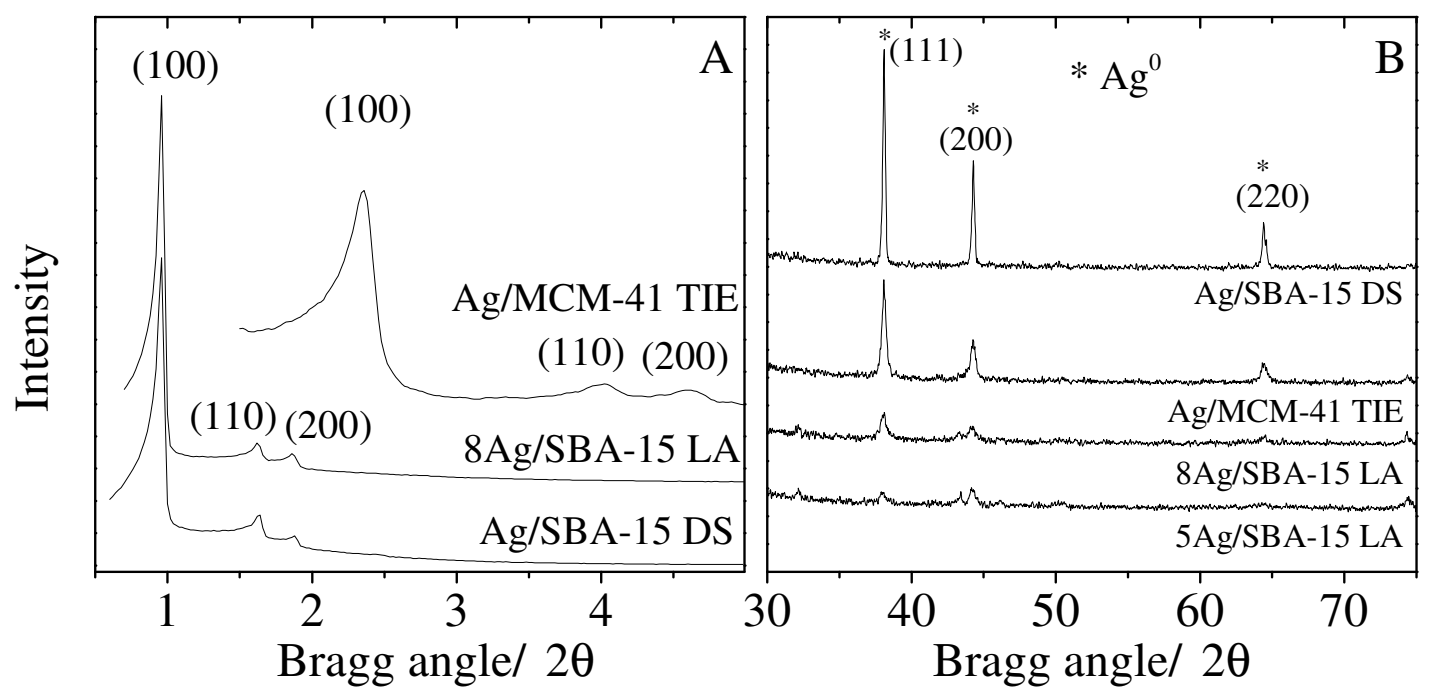

Fig. 1 Small angle (A) and wide angle (B) XRD patterns.

Table 1 Textural properties and silver content of the studied samples

\begin{tabular}{llllll}
\hline Sample & $\begin{array}{l}\text { Ag content } \\
\text { wt.\% }\end{array}$ & $\begin{array}{l}\mathrm{a}_{0}{ }^{\mathrm{a}} \\
\mathrm{nm}\end{array}$ & $\begin{array}{l}\text { BET surf. area } \\
\mathrm{m}^{2} / \mathrm{g}\end{array}$ & $\begin{array}{l}\text { Pore vol. } \\
\mathrm{cm}^{3} / \mathrm{g}\end{array}$ & $\begin{array}{l}\text { Pore diam. } \\
\mathrm{nm}\end{array}$ \\
\hline MCM-41 & - & 4.4 & 1175 & 0.97 & 2.7 \\
Ag/MCM-41 TIE & 5.6 & 4.3 & 927 & 0.76 & 2.6 \\
SBA-15 & - & 10.2 & 1012 & 1.20 & 6.0 \\
Ag/SBA-15 DS & 7.2 & 10.6 & 698 & 1.08 & 6.6 \\
5Ag/SBA-15 LA & 4.7 & 10.2 & 880 & 1.02 & 6.0 \\
8Ag/SBA-15 LA & 8.0 & 10.2 & 865 & 1.01 & 6.0 \\
\hline
\end{tabular}

${ }^{\mathrm{a}}$ Unit cell parameter $\left(\mathrm{a}_{0}=2 \mathrm{~d}_{100}(3)^{-1 / 2}\right)$.

${ }^{\mathrm{b}}$ Mean pore diameter calculated by the BJH method.

have shown a unit cell and pore size similar to the parent SBA-15 material, indicating that the procedure did not affect the initial silica structure.

At higher angles the XRD pattern of each sample shows the presence of metallic silver phase. The $\mathrm{Ag}^{0}$ reflections indicate the formation of silver particles larger than $5 \mathrm{~nm}$. These particles can be either bound or not bound to the outer surface of the silica particles.

The most intensive reflections can be observed on the XRD pattern of Ag/SBA-15 DS sample; whereas the Ag/SBA-15 LA samples having silver contents in the same range show weaker and broader lines. In general, the intensity of these $\mathrm{Ag}^{0}$ reflections are lower than the expected ones considering the silver content. This can be explained by the confinement of silver nanoparticles smaller than $5 \mathrm{~nm}$ size inside the channels of the hosting silica structure. Also, the incorporation of silver ions into mesopore walls of the silica cannot be excluded. 


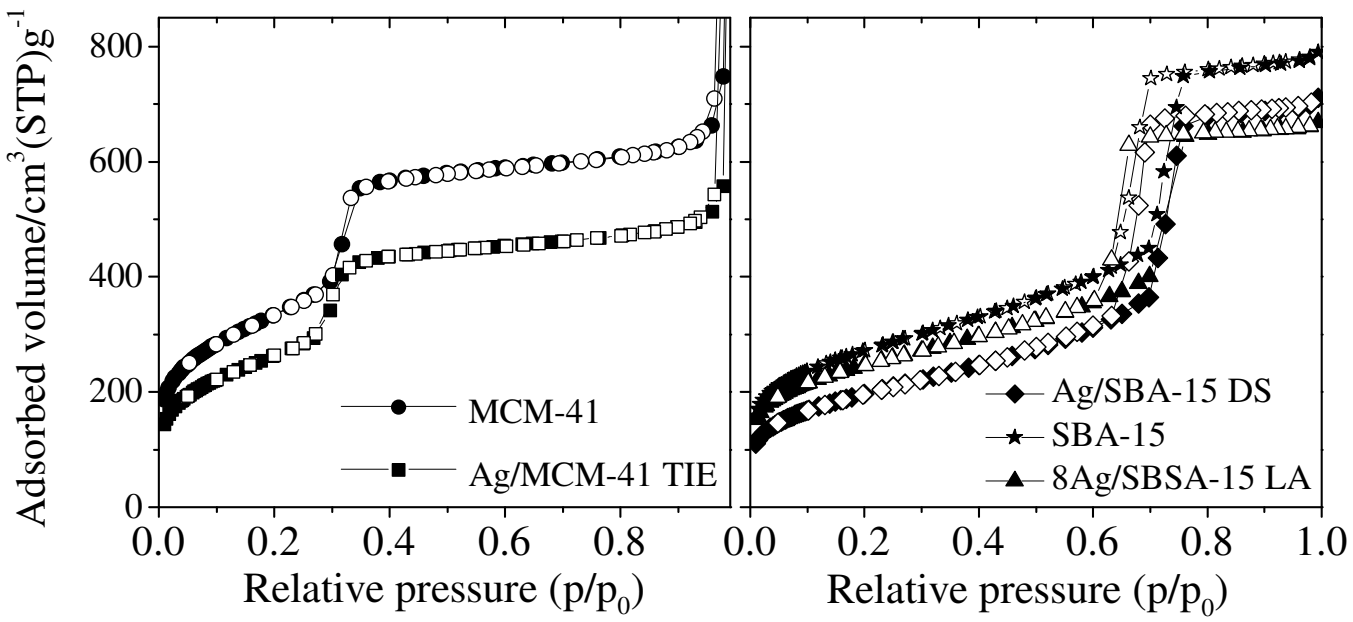

Fig. $2 \mathrm{~N}_{2}$ adsorption isotherms at $-196{ }^{\circ} \mathrm{C}$.

However, in contrast to two and trivalent transition metals $(\mathrm{Cu}, \mathrm{Ni}, \mathrm{Co}, \mathrm{Fe})$ [31], the monovalent Ag ions cannot strongly interact with silanol groups, i.e., there is not a strong interaction between the silver ions and the silica support. The average crystallite size of the metallic silver, determined by the Sherrer method was about $45 \mathrm{~nm}$ for the Ag/MCM-41TIE and Ag/SBA-15 LA samples, whereas it was slightly over $1 \mu \mathrm{m}$ for the Ag/SBA-15 SD sample.

The $\mathrm{N}_{2}$ adsorption data supporting the above observations are reported in Fig. 2. The textural parameters of the preparations together with the evaluated specific surface area by BET method are summarized in Table 1. The nitrogen physisorption isotherms of pure and silver modified MCM-41 materials show type IV adsorption isotherm with a capillary condensation step between 0.2 and 0.3 relative pressures. Compared to parent silica material, the specific surface area and the total pore volume of the Ag/MCM-41 TIE sample are slightly lower, suggesting a partial structural destruction. The type IV $\mathrm{N}_{2}$ adsorption isotherms of the Ag/SBA-15 samples show type H1 hysteresis loop, characteristic for the SBA-15 structures. The specific surface area and pore volume of the Ag/SBA-15 samples, prepared either by direct synthesis or by laser ablation, are hardly lower than the corresponding ones of the bare silica SBA-15. The minor changes may reflect some pore blocking by small silver nanoparticles present within the channels.

Modification by silver does not influence the original morphology of MCM-41 and SBA-15 materials as evidenced by TEM pictures (Figs. 3-4). The channel system of the Ag/MCM-41 TIE sample, having spherical particles of about $100 \mathrm{~nm}$ diameter, is well preserved. Silver nanoparticles of different sizes from 5 to $20 \mathrm{~nm}$ can be observed on the images of Figs. $3 \mathrm{~A}$, B. These findings are in accordance with the XRD results showing the presence of a separate 


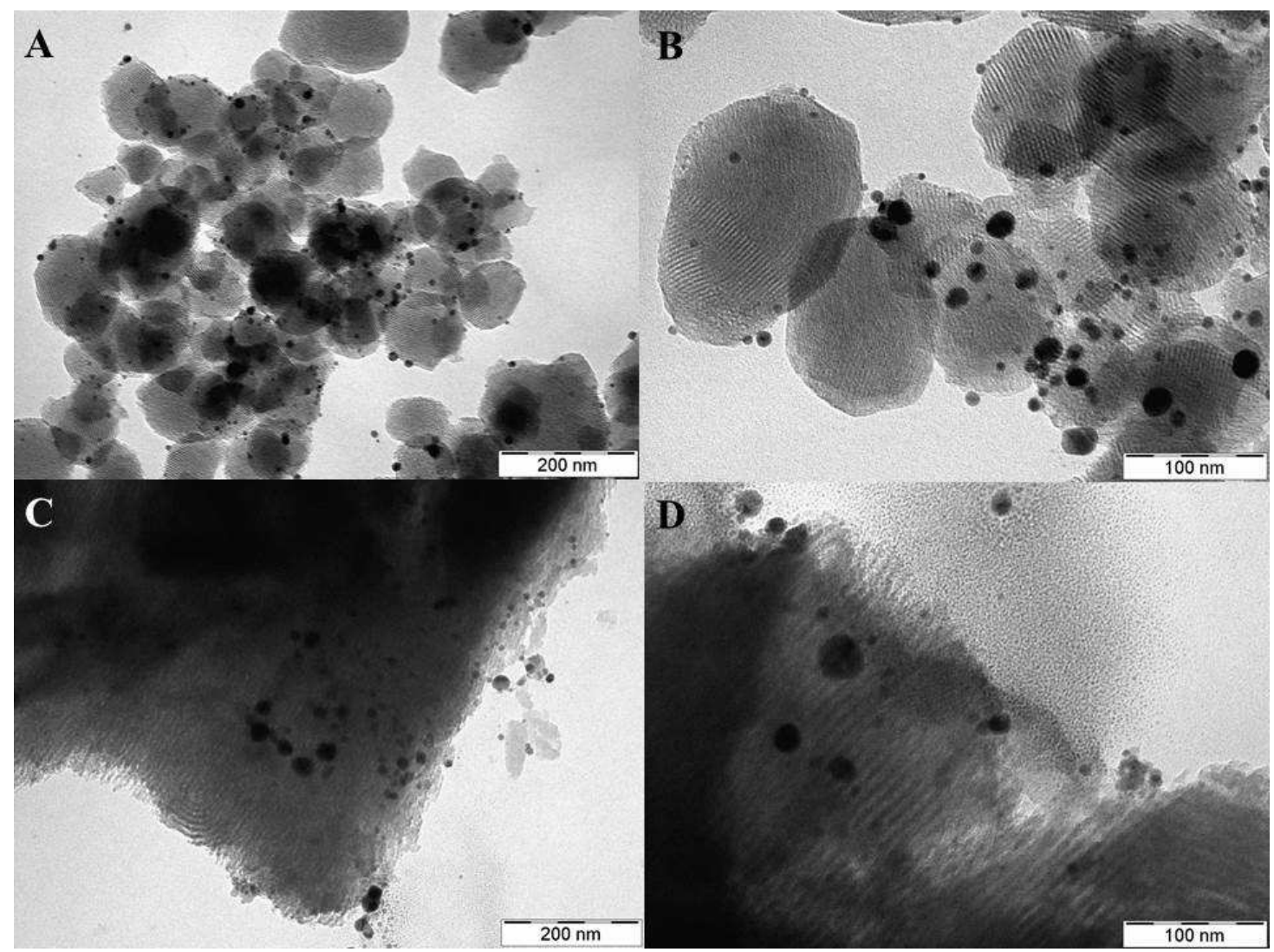

Fig. 3 TEM images of Ag/MCM-41 TIE (A, B), and Ag/SBA-15 DS (C, D) samples.

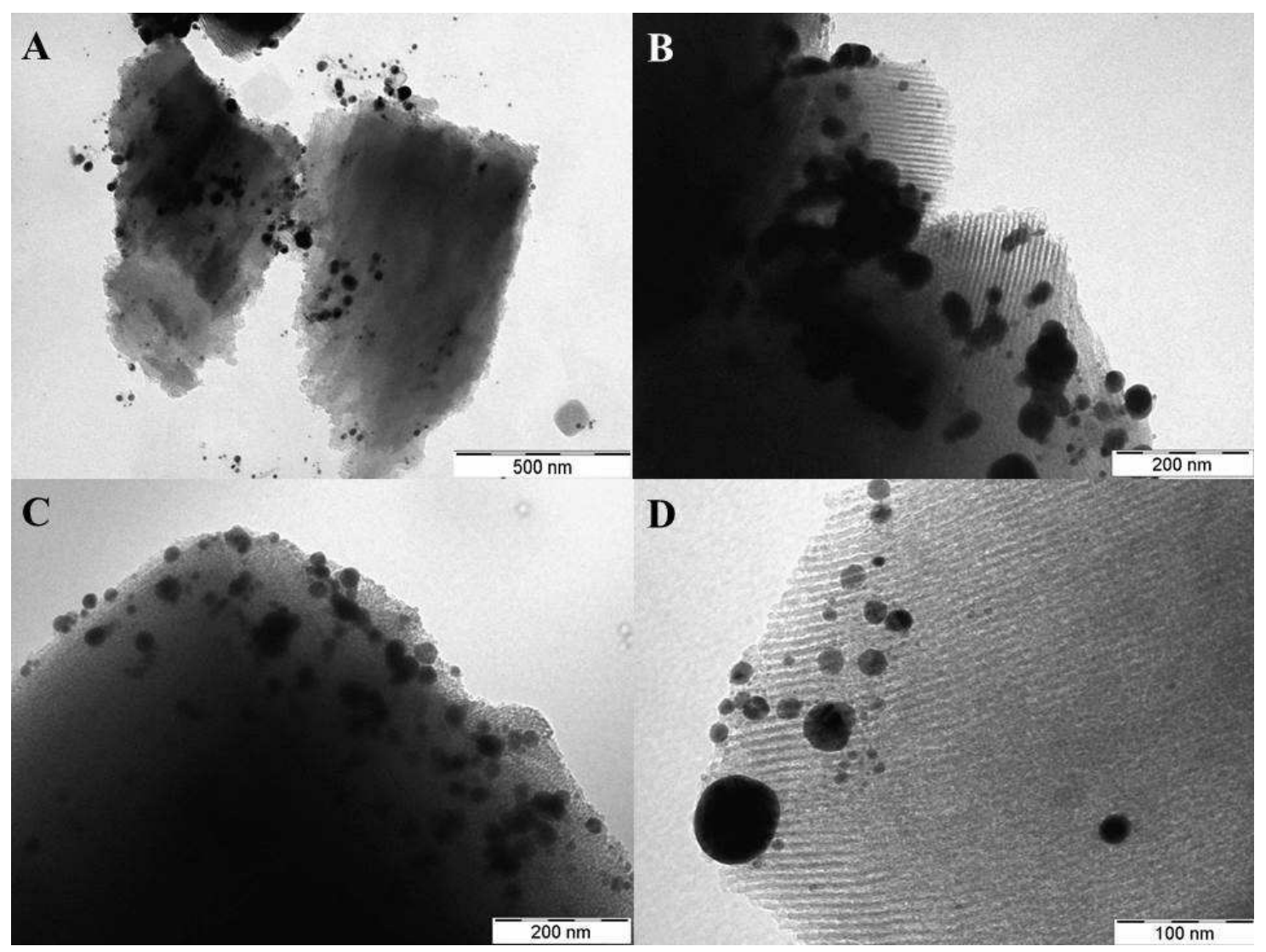

Fig. 4 TEM images of 5Ag/SBA-15 LA (A, B) and 8Ag/SBA-15 LA (C, D) samples. 
silver phase placed outside the spherical silica particles. The TEM images of the Ag/SBA-15 DS sample exhibits slightly different pictures (Figs. 3 C-D). There are larger 5-50-nm size silver nanoparticles on the external surface of the silica particles, and smaller $5 \mathrm{~nm}$ particles inside the silica mesopores. The TEM images of Ag/SBA-15 samples prepared by laser ablation method (Fig. 4) show similar features. Silver particles of 5-50-nm size can be observed on the outer surface of the silica carrier, and also smaller particles can be discerned to be penetrated into the channels. No large silver particles, neither separated nor attached to silica particles have been detected. This is in accordance with the XRD results, showing, on the contrary of Ag/MCM-41, small amount of silver phase with broadened reflections. The laser ablation seems to give smaller and more uniform size metallic silver nanoparticles adhered to the surface of the silica support than the procedure of direct synthesis.

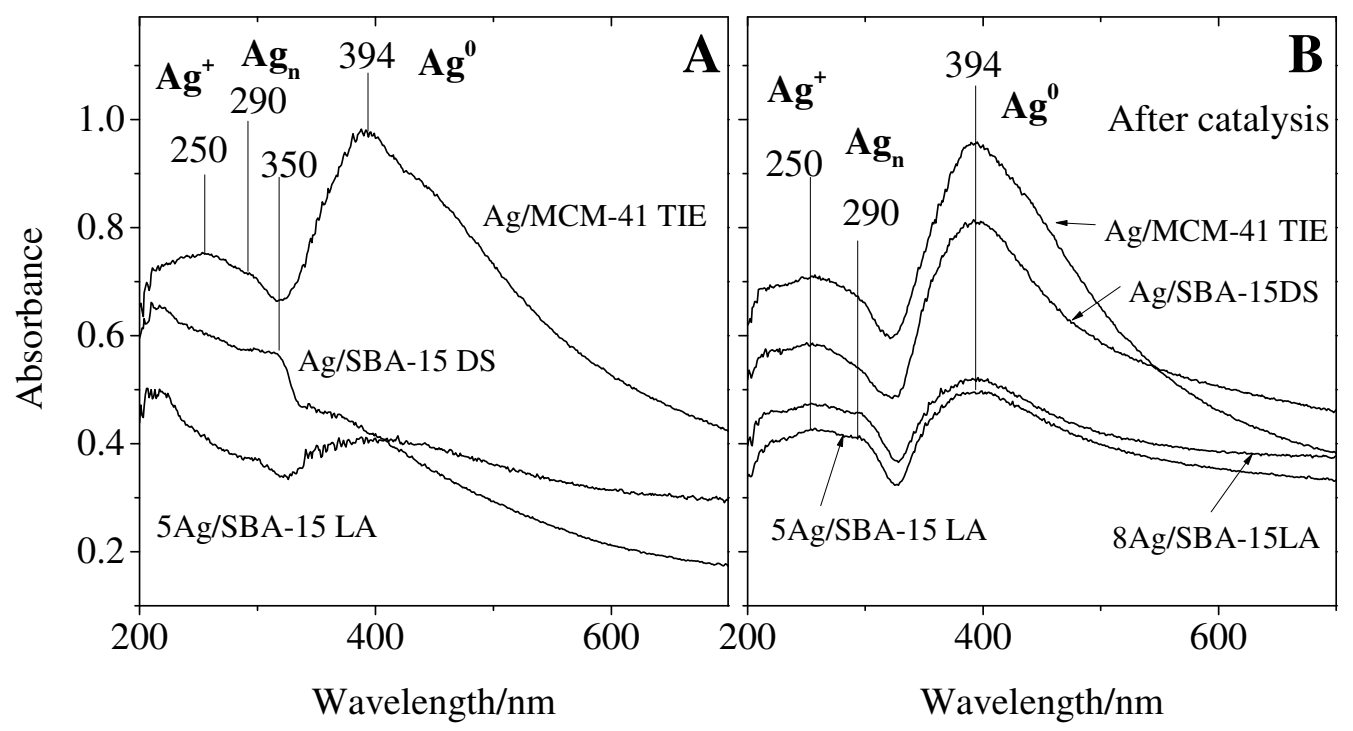

Fig. 5 DR UV-vis spectra of silver supported onto nanostructured silica materials before and after catalytic experiments.

During high temperature template removal the silver ions incorporated into the silica mesoporous structure can leave the framework and agglomerate to larger particles. The narrower pores of the MCM-41 silica can hinder this agglomeration process, on the contrary of the larger pores of the SBA-15 support.

Diffuse reflectance UV-vis spectroscopy is a useful tool to follow the state of silver ions together with that of nanoparticles. Spectra of various silver mesoporous silica materials are shown in Figs. 5A-B. Three main features can be identified: the peaks between 210-250 nm, attributed to the $4 \mathrm{~d}^{10}$ to $4 \mathrm{~d}^{9} \mathrm{~s}^{1}$ transition of $\mathrm{Ag}^{+}$ions, the bands at 290 and $350 \mathrm{~nm}$, assigned to 
the presence of $\mathrm{Ag}_{\mathrm{n}}$ nanoclusters and the wide band around $400 \mathrm{~nm}$ that comes from surface plasmon resonance (SPR) of metallic silver nanoparticles [32-34]. The spectrum of the Ag/MCM-41 TIE sample shows a very intense and asymmetric SPR band, indicating a high amount of metallic silver nanoparticles in the diameter range of 5-45 nm with different morphologies (spherical and elongated). The UV-vis spectra of the Ag/SBA-15 samples exhibit, in general, lower intensity SPR band, especially the spectrum of the Ag/SBA-15 DS sample and, in agreement with XRD and TEM data, these display even the presence of larger silver particles. For both $\mathrm{Ag} / \mathrm{SBA}-15$ systems the $\mathrm{Ag}$ cluster and ionic components of the $\mathrm{UV} / \mathrm{vis}$ spectra are greater than the SPR band.

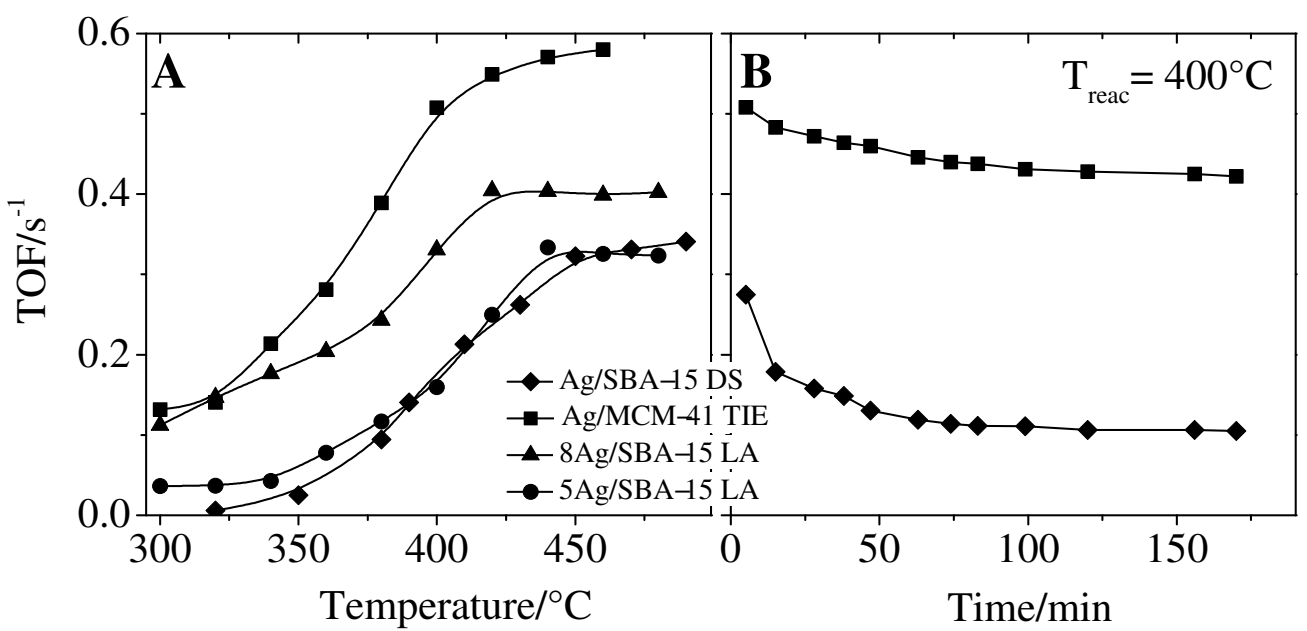

Fig. 6 Total oxidation of toluene on silver-mesoporous silica support. Catalytic activity vs. temperature (A) and time on stream experiments at $400^{\circ} \mathrm{C}$ (B). Prior to the catalytic tests the samples were calcined in situ in the reactor for 1 hour at $450^{\circ} \mathrm{C}$ in air flow.

\subsection{Catalytic activity in toluene oxidation}

Catalytic total oxidation is an efficient method for the emission abatement of volatile organic compounds (VOCs). Supported noble metals (Pt, Pd) are widely applied catalysts for this process. Research is, however, focusing on the development of less expensive and environmentally more friendly catalysts. It has been shown that nanosized silver particles supported onto silica can be promising for such purposes [34,35]. For such a reason our nanostructured silica supported silver catalysts were tested in the total oxidation of toluene. The catalytic activities in dependence of temperature are presented in Fig. 6 A. Carbon dioxide is the only carbon-containing product found in all experiments. Comparing the 
catalytic activities of Fig. 6A, it is clear that higher catalytic conversion is provided by the Ag/MCM-41 catalyst than silver SBA-15 samples. Consequently, the MCM-41 mesoporous silica seems to be a more suitable support for the formation of metallic silver species with favorable catalytic properties for toluene oxidation.

The Ag/SBA-15 samples show lower oxidation activities than the Ag/MCM-41 catalyst. Among these, the $8 \mathrm{Ag} / \mathrm{SBA}-15 \mathrm{LA}$ catalyst is more active than both the $5 \mathrm{Ag} / \mathrm{SBA}-15 \mathrm{LA}$ and Ag/SBA-15 DS samples. Investigating the time on stream behavior of the catalysts, the Ag/SBA-15 DS catalyst showed fast deactivation, whereas the Ag/MCM-41 TIE one was more stable (Fig. $6 \mathrm{~B}$ ). The lower activity of the 5Ag/SBA-15 LA sample can be related to its lower metal content, whereas the unfavorable metal dispersion could be responsible for the poor performance of the chemically synthesized Ag/SBA-15 sample.

Regarding the VOC oxidation activity of supported noble metal catalysts, the metal dispersion, particles size, preparation method, type of precursors and nature of the support, can play a crucial role [36]. The fresh and spent catalysts investigated by DR UV-vis spectroscopy (Figs. 5 A-B) show that the distribution of silver ions and particles in the Ag/MCM-41TIE catalyst hardly changed upon use. For such a sample the asymmetry of the SPR band slightly decreased after its use indicating that some restructuring of the larger elongated nanoparticles could take place. In contrast, the silver particles in the Ag/SBA-15 DS catalyst became totally re-dispersed after reaction. The UV-vis spectrum, in fact, shows that the fresh catalyst contains mainly ionic and nanoclustered silver, whereas the SPR band is negligible. In accordance with these findings the XRD results showed that the fresh catalyst contains larger than nanosize silver particles. However, after catalytic reaction an intense SPR band appeared at $394 \mathrm{~nm}$ in the spectrum of the spent catalyst, evidencing that the metal particles became re-distributed on the surface of SBA-15 support. The adsorption interaction between the particles and the reactants weakens the metal-metal bond and mobilize the metal atoms at the elevated reaction temperature. This phenomenon can be discussed in terms of adsorbate-induced reduction of the surface-free energy. Oxygen adsorption is known to result in a reduction of the surface-free energy of solids. Similar re-dispersion of metallic silver on the SBA-15 surface was reported by Zhang et al. [34] upon high temperature oxygen treatment of the catalyst. This might be the reason for the lower catalytic stability of the Ag/SBA-15 DS sample. The Ag/SBA-15 catalysts prepared by laser ablation showed less significant re-structuring. The SPR band of the catalyst became somewhat stronger upon use. In any case, the homogeneously dispersed small metallic nanoparticles were quite efficiently stabilized by the silica surface and, therefore, showing favorable catalytic properties. 


\section{Conclusions}

In this work, it is reported for the first time, that silver nanoparticles can be loaded on SBA-15 support by using the ultra-short pulsed laser ablation in liquid approach. Comparing the dispersion of metallic silver particles on different supports prepared by laser ablation or chemical methods it has been found that smaller and more homogeneously dispersed nanoparticles can be fabricated by the former. It is shown that nanostructured silica supporting metallic silver nanoparticles are suitable catalysts for oxidation reaction of toluene. For this outcome the dispersion of the metal nanoparticles plays a key role in the catalytic activity. Since $8 \mathrm{Ag} / \mathrm{SBA}-15 \mathrm{LA}$ shows a better catalytic performance than chemically synthesized Ag/SBA-15 DS, it can be drawn that finely and uniformly dispersed nanoparticles confined in small nanopores or stabilized on the surface of silica support can be necessary to obtain an active and stable silver catalyst. Nevertheless, the Ag load provided by laser ablation on SBA-15 silica support can play an important role in catalytic VOC oxidation as it is shown by the 5Ag/SBA-15 LA lower capability in oxidizing toluene. In future, more experimental works on laser ablation in liquid can be planned for choosing the appropriate support to be used as well as the laser ablation parameters and method to be followed for enhancing the catalytic activity of these systems. Furthermore, the most suitable metal type and its loading together with controlled tailored nanostructures can be defined for establishing the absolute ability of catalysts prepared by ultra-short pulsed laser ablation in liquid in oxidizing different VOCs.

\section{Acknowledgements}

This paper draws on work undertaken as part of the project CLaN (Combined Laser Nanotechnology) co-financed by the Operational Programme ERDF Basilicata 2007-2013. 


\section{References}

[1] A. De Bonis, A. Galasso, N. Ibris, A. Laurita, A. Santagata, R. Teghil, Appl. Surf. Sci. 268 (2013) 571-578

[2] A. De Giacomo, A. De Bonis, M. dell'Aglio, O. De Pascale, R. Gaudiuso, S. Orlando, A. Santagata, G.S. Senesi, F. Taccogna, R. Teghil, J. Phys. Chem. C 115 (2011) 5123-5130

[3] A. Santagata, A. De Bonis, A. De Giacomo, M. dell'Aglio, A. Laurita, G.S. Senesi, R. Gaudiuso, S. Orlando, R. Teghil, G.P. Parisi, J. Phys. Chem. C 115 (2011) 5160-5164

[4] K. Sasaki, N. Takada, Pure Appl. Chem. 82 (2010) 1317-1327

[5] F. Mafune, J. Kohno, Y. Takeda, T. Kondow, H. Sawabe., J. Phys. Chem. B 104 (2000) 8333-8337

[6] F. Mafune, J. Kohno, Y. Takeda, T. Kondow, H. Sawabe., J. Phys. Chem. B 104 (2000) 9111-9117

[7] F. Mafune, J. Kohno, Y. Takeda, T. Kondow, H. Sawabe, J. Phys. Chem. B 105 (2001) $5114-5120$

[8] A. Henglein, J. Phys. Chem. 97 (1993) 5457-5471.

[9] M.S. Yeh, Y.S.Yang, Y.P. Lee, H.F. Lee, Y.H. Yeh, C.S. Yeh, J. Phys. Chem. B 103 (1999) 6851-6857

[10] J. Neddersen, G. Chumanov, T.M. Cotton, Appl. Spectrosc. 47 (1993) 1959-1964

[11] M.S. Sibbald, G. Chumanov, T.M. Cotton, J. Phys. Chem. 100 (1996) 4672-4678

[12] A. De Giacomo, M. dell'Aglio, A. Santagata, R. Gaudiuso, O. de Pascale, P. Wagener, G.C. Messina, G. Compagnini, S. Barcikowski, Phys. Chem. Chem. Phys. 15 (2013) 3083-3092

[13] A. De Bonis, M. Sansone, L. D’ Alessio, A. Galasso, A. Santagata, R. Teghil, J. Phys. D: Appl. Phys. 46 (2013) 44530-9

[14] V. Amendola, M. Meneghetti, Phys. Chem. Chem. Phys. 15 (2013) 3027-3046

[15] S. Barcikowski, G. Compagnini, Phys. Chem. Chem. Phys. 15 (2013) 3022-3026

[16] P. Wagener, S. Barcikowski, N. BårschPhotonik Int., 1 (2011) 20-23

[17] J. Zhu, Z. Konya, V.F. Puntes, I. Kiricsi, C.X. Miao, J.W. Ager, A.P. Alivisatos, G.A. Somorjai, Langmuir, 19 (2003) 4396-4401

[18]Z. Kónya, V.F. Puntes, I. Kiricsi, J. Zhu, J.W. Ager, M.K. Ko, H. Frei, P. Alivisatos, G.A. Somorjai, Chem. Mater. 15 (2003) 1242-1248

[19] S. Rojas, F.J. Garcı-Garcıa, S. Jaras, M.V. Martınez-Huerta, J.L. Garcıa Fierro, M. Boutonnet, Appl. Catal. A: Gen. 285 (2005) 24-35 
[20] S. Bhattacharyya, A. Gabashvili, N. Perkas, A. Gedanken, J. Phys. Chem. C 111 (2007) $11161-11167$

[21] S. Bhattacharyya, A. Gedanken J. Phys. Chem. C 112 (2008) 659-665

[22]D.S. Gopala, R.R. Bhattacharjee, R. Richards, Appl. Organometal. Chem. 27 (2013) 1-5

[23] S. Hashimoto, T. Uwada, H. Masuhara and T. Asahi, J. Phys. Chem. C 112 (2008) 15089-15093

[24] G.-P.Yong, D. Tian, H.-W. Tong, S.-M. Liu, J. Mol. Catal. A: Chemical 323 (2010) 4044

[25] C.M. Maroneze, L.P. da Costa, F.A. Sigoli, Y. Gushikem, I.O. Mazali, Synth. Met. 160 (2010) 2099-2103

[26] Y. Chi, L. Zhao, Q. Yuan, Y. Li, J. Zhang, J. Tu, N. Li, X. Li, Chem. Eng. J. 195-196 (2012) 254-260

[27] S. Huh, J. Wiench, J.-ChYoo, M. Pruski, V.S.-Y. Lin, Chem. Mater. 15 (2003) 42474256

[28] W. Gac, A. Derylo-Marczewska, S. Pasieczna-Patkowska, N. Popivnyak, G. Zukocinski, J. Mol. Catal. A: Chem. 268 (2007) 15-23

[29] W. Zhu, Y. Han, L. An, Micropor. Mesopor. Mater. 80 (2005) 221-226

[30] D.Zhao, J.Feng, Q. Huo, N. Melosh, G.H. Fredrickson, B.F. Chmelka, G.D.Stucky, Science 279 (1998) 548-552

[31]A. Szegedi, Z. Kónya, D. Méhn, E. Solymár, G. Pál-Borbély, Z.E. Horváth, L.P. Biró, I. Kiricsi, Appl. Catal. A: Gen. 272 (2004) 257-266

[32] U. Kreibig, M. Vollmer, Optical Properties of Metal Clusters, Springer-Verlag, New York, 1995

[33]N. Bogdanchikova, F.C. Meunier, M. Avalos-Borja, J.P.Breen, A. Pestryakov, Appl. Catal. B: Environ. 36 (2002) 287-297

[34]X. Zhang, Z.Qu, F.Yu, Y.Wang, J. Catal. 297 (2013) 264-271

[35] Y.Sohn, J. Mol. Catal. A: Chem. 379 (2013) 59- 67

[36] L.F. Liotta, Appl. Catal. B: Environ. 100 (2010) 403-412. 